\title{
Effect of Microwave Heating on the Quality and Shelf Life of Whole Grain Wheat Flour under Air-Conditioned Storage
}

\author{
A. Inthuja ${ }^{1}$, V. Anujaa ${ }^{2}$, T. Mahendran ${ }^{1}$ and M. R. Roshana $^{1 *}$ \\ ${ }^{1}$ Department of Agricultural Chemistry, Faculty of Agriculture, Eastern University, Sri \\ Lanka. \\ ${ }^{2}$ Department of Research and Development, Prima Ceylon (Pvt.) Ltd, Chinabay, \\ Trincomalee.
}

\begin{abstract}
A study was conducted to evaluate the quality changes that could be occurred in the whole grain wheat flour during the storage and also to study the effect of microwave heating in the quality of the wheat flour. Whole grain wheat flour was packed in low density polyethylene bags separately as microwaved and nonmicrowaved and the quality changes were assessed for 12 weeks under airconditioned storage temperature of $27^{\circ} \mathrm{C}$. The quality characteristics such as smell, sieve test, long moisture, moisture NIR, protein NIR, ash NIR, wet-gluten, fat acidity, colour and weevil count were evaluated in 2 weeks interval. Fat and fiber content were evaluated in 4 weeks interval. Healthy cake was prepared from microwaved and non-microwaved flour and the sensory characteristics were evaluated using seven point hedonic scale method at the end of 4 weeks. The results of the study revealed that there were no significant differences $(p>0.05)$ in the quality parameters of whole grain wheat flour in protein, ash, smell, fat and fiber whereas moisture, wet gluten, colour and the fat acidity changed significantly during the 12 weeks of storage. There was no any weevil infestation found in both flours. Sensory characteristics of the healthy cake were not affected by storage in both microwaved and non-microwaved flours. It was found from this study that, whole grain wheat flour can be stored under air-conditioned temperature of $27^{\circ} \mathrm{C}$ for 12 weeks from the date of manufacture.
\end{abstract}

Keywords: healthy cake, physico-chemical properties, sensory evaluation, whole grain wheat flour.

${ }^{1}$ Corresponding author: mrroshana30@gmail.com

iD https://orcid.org/0000-0002-8634-6699 


\subsection{INTRODUCTION}

Wheat (Triticum aestivum) is one of the most important food crops that man has cultivated for thousands of years. Wheat is unique in that it forms viscoelastic dough which is able to retain gas bubbles formed by fermentation. As a result, aerated baked products with desirable texture can be made from wheat flour [1]. Wheat is an important source of energy, carbohydrates, protein, fiber, B vitamins, iron, calcium, phosphorus, zinc, potassium and magnesium. This is true especially for whole wheat flour [2]. Its success depends partly on its adaptability and high yield potential but also on the gluten protein fraction which confers the viscoelastic properties that allow dough to be processed into bread, pasta, noodles and other food products. However, wheat products are also suggested to be responsible for a number of adverse reactions in human, including intolerances (celiac disease) and allergies (respiratory and food).

A diet rich in whole-grain foods provides protection against some chronic diseases, including cardiovascular diseases, diabetes and many types of cancer. During milling, the bran and germ layers are removed and the remaining starchy endosperm which contains few antioxidant compounds is ground into flour to make various products. Whole-grain products, retain bran and germ which provide biologically active antioxidants that may act independently or synergistically with fiber to reduce the risk of a number of diseases [3]. Consumers have demanded more whole grain products during the last decade due to the known benefits associated with its consumption and the prevention of cardiovascular diseases and certain types of cancer such as colon cancer, reduction of the risk of type- 2 diabetes and its prebiotic potential [4].

Current and future concerns include sustaining wheat production and quality with reduced inputs of agrochemicals and developing lines with enhanced quality for specific end-uses, notably for bio fuels and human nutrition. Indeed, about $56 \%$ of grocery shoppers switched to whole grain bread, and the consumption of other whole grain products have been increasing. Due to this demand, whole wheat flour production was about $2 \%$ of total wheat flour production in 2000 [5] compared to $5 \%$ in 2010 [6]. By applying heat treatment, it is possible to modify the physical and rheological properties. The primary effect of heat treatment is denaturation of the proteins, partial reduction or inactivation of alpha-analyze, and partial gelatinization of the starch. Understanding of relationship between heat 
transfer, thermal properties of food, heating medium, thermodynamics and the functionality of the resulting heat-treated flour is of critical importance [7].

Wheat flours continue to be living biological stuffs also during the ensuing storage. All processes connected with maturation work on for several days after milling and their influence on the flour quality depends on the ambient storage conditions. Flour is a very hygroscopic material and its moisture changes with the changes in temperature and humidity of the store environments. Subsequently a point is reached where further storage no longer seems to be conducive for baking and the bread making properties of flour deterioration. Flour components such as protein, starch and lipid change and these changes directly affect dough rheological and baking characteristics [8]. The baking properties of freshly harvested wheat or freshly milled wheat flour have been reported to improve during storage for a time depending on the nature of the flour and conditions of storage. Therefore, this study was conducted to determine the shelf-life of whole grain wheat flour at air-conditioned environment, determine the effect of microwaving on shelf-life and quality of whole grain wheat flour and to study the physicochemical and nutritional changes of flour during the storage.

\subsection{MATERIALS AND METHODS}

\subsection{Sample preparation}

This study was conducted at the Department of Research and Development, Prima Ceylon (Pvt.) Limited, Chinabay, Trincomalee. This research was carried out to evaluate the shelf life of healthy flour in air-conditioned environment and to evaluate the effect of microwaving on physiochemical and baking properties of flour. Study was conducted for 12 weeks. Freshly milled sample and microwaved sample of whole grain flour were packed in low density polyethylene bags separately and stored in air-conditioned room at $27^{\circ} \mathrm{C}$. Every week samples were taken and physico-chemical and biological analysis were carried out. Product development (Healthy cake) and sensory analysis were carried out at the end of every 4 weeks.

\subsection{Physico-Chemical Properties Analysis}

Physico-chemical properties are smell test of flour, sieve test (over tail and weevil count), long moisture, moisture NIR (Near Infrared Ray), protein NIR, ash NIR, 
wet gluten, colour and fat acidity which were evaluated in two weeks interval. Fat, fiber and product development were conducted once in every 4 weeks. Long moisture analysis, wet gluten, fat, fiber and fat acidity were analyzed according to the recommended AACC [9] method. Moisture NIR, ash NIR and protein NIR were analyzed by using NIR machine. Colour test was done using spectrophotometer (Model-UV-Visible 2240IR) [10]. Typically for whole grain smell test was done to check the rancid odour [11]. Sieve test is conducted to measure the over tail percentage in the flour. Flour was sieved by using $350 \mu \mathrm{m}$ sieve. The coarse grain particles remains in the sieve known as over tail, was measured and changed into percentage or $\mathrm{g} / \mathrm{kg}$.

\subsection{Biological Studies}

Major aspect of biological analysis is to find out weevil. Sieving test was done to check the presence of storage pest contamination in the flour which is a clear indicator of the flour quality. The presence of weevil in the flour sample says that the flour quality deterioration [12].

\subsection{Product Development of Healthy Cake and Sensory Evaluation}

Margarine and sugar were mixed well until sugar get dissolved well. Then eggs were added one by one and beat well for a creamy texture by using electrical beater. Meanwhile measured amount of baking powder was added with right proportion of flour and both were mixed well by sieving 2-3 times. Then flour was added and mixed. Finally vanilla was added. Dough was transferred into cake pan and baked in oven. Sensory evaluation of the healthy cake was performed on general appearance, aroma, colour, taste, texture and mouth feel using 7 point hedonic scale by panel of 30 trained judges. The scores for these parameter were summed up and by averaging these, overall acceptability score of healthy cake was calculated.

\subsection{Statistical Analysis}

Data of the nutritional parameters were analyzed by Analysis of Variance (ANOVA) $(\alpha=0.05)$ and the differences between means was compared using Duncan's Multiple range Test (DMRT). Complete Randomized Design (CRD) was used. Both nutritional and organoleptic analysis was done through Statistical Analysis System (SAS) software statistical package. 


\section{0 RESULTS AND DISCUSSION}

\subsection{Physico-chemical properties}

\subsubsection{Smell Test and Sieve Test}

According to the results which were obtained through 12 weeks study period, smell of the whole grain flour remained unchanged. For whole grain flour there was no any deterioration in shelf-life in the case of sensory characteristics due to the storage period. No more differences were not observed up to $12^{\text {th }}$ week between microwaved and non-microwaved flours. Smell is the indicator of the growth of microorganism especially fungal infestation due to changes in moisture content and rancidity due to the presence of fat acidity. The data obtained from sieve test, whole grain wheat flour was $100 \%$ over tail free throughout the storage period (12 weeks) for both conditions microwaved and non-microwaved. So flour quality remained unchanged for 3 months in case of over tail.

\subsubsection{Long Moisture Content}

Long moisture is an indicator of grain storability. The Figure 1 shows that impact of storage period on the long moisture content of microwaved and nonmicrowaved whole grain wheat flour and also compares the difference between microwaved and non-microwaved flours. According to the statistical analysis, there was no significance differences $(p>0.05)$ in long moisture content due to the storage. But, the study says that microwaving significantly affected the long moisture content of the flour. It is proved from the figure that there was a great impact on long moisture content due to microwaving. Long moisture content of microwaved flour was reduced by $2.0-2.5 \%$. During microwaving certain level of moisture was removed from flour [13]. This reduced moisture level helps to prevent the microbial growth specially fungus and microorganism (weevil). 


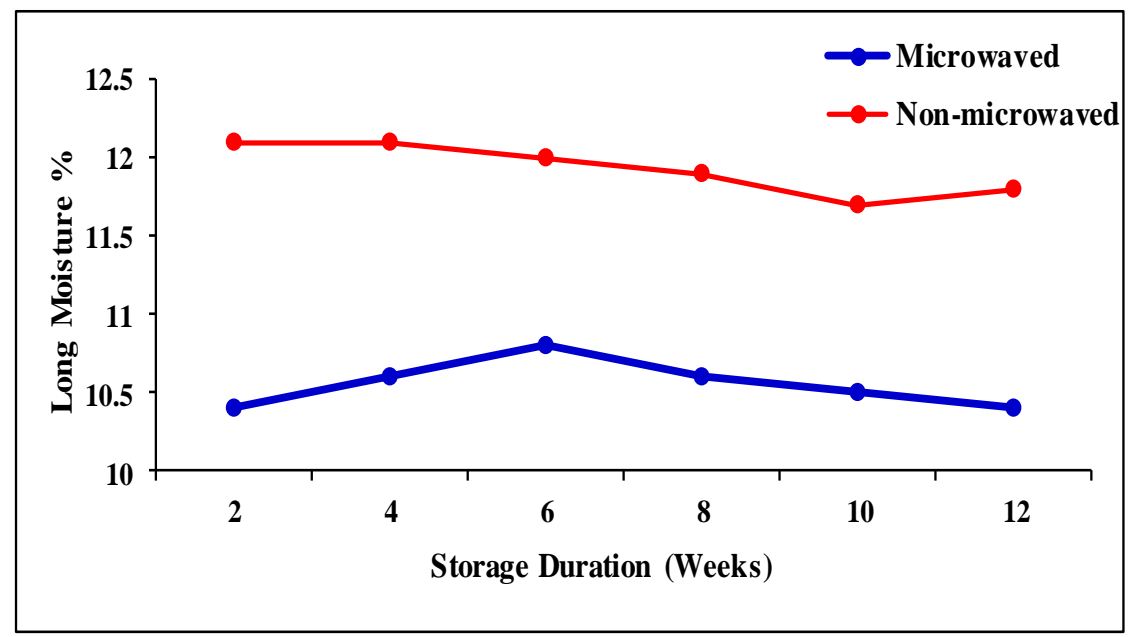

Figure 1: Impact of Storage Period and Microwaving on Long Moisture Content of Whole Grain Wheat Flour

\subsubsection{Moisture NIR (Near Infrared Ray)}

Table 1 elaborates the moisture content changing pattern of whole grain wheat flour for 12 weeks storage period and also shows the differences between microwaving and non-microwaving flours. As previously explained, microwaving reduces the amount of moisture present in the flour. Moisture content of the microwaved flour fluctuated between $10.5-11.0 \%$ whilst the moisture content of non- microwaved flour was $1.0-1.5 \%$. According to the statistical analysis, there was no significant effect $(\mathrm{p}>0.05)$ on moisture content of the flour due to storage time. But, significance differences $(\mathrm{p}<0.05)$ were observed due to microwaving.

\subsubsection{Protein NIR}

Table 1 shows the impact of storage on the protein content of the whole grain wheat flour and compares the changes of protein content of microwaved and nonmicrowaved flour for 12 weeks period. Protein content of microwaved flour was slightly higher than the non-microwaved flour throughout the study period. Microwaving had a slight impact on the protein content of the whole grain wheat flour. Results of the statistical analysis, there was no significance effect ( $p>0.05$ ) on the protein content of the flour due to the storage and microwaving. 


\subsubsection{Ash NIR}

Ash content gives a quantitative estimation of the minerals available in a given food product [14]. Changes of both microwaved and non-microwaved flours during the storage are shown in Table 1 . Thus frequent and steady fluctuations were observed during 12 weeks of storage of flour. Ash content between microwaved and non-microwaved flour were not shown a prominent differences due to microwaving during the study.

\subsubsection{Wet-Gluten}

Lengthening the storage of wheat flour gradually influences the decreasing quantity of gluten content. As shown in Figure 2, at the beginning wet-gluten content of the non-microwaved flour was slightly higher than microwaved flour, but later on wet-gluten content of both flours remained nearly same percentage. The wet-gluten content of microwaved flour is $30.1 \%$ at the beginning and it is reduced to $23.5 \%$ at the end of $12^{\text {th }}$ week.

\subsubsection{Fat}

The fat content of microwaved and non-microwaved whole grain wheat flour is shown in Table 2. The fat content of fresh milled whole grain wheat flour was estimated as $3.37 \%$, but it diminished to $3.13 \%$ at the end of 12 weeks storage. For microwaved sample, fat content at the beginning was $4.53 \%$ and it also decreased to $3.29 \%$ at the end. The decrease in fat could be attributed to the lipolytic activities of the enzyme lipase and lipoxidase [15]. 
Table 1: Impact of Storage Period and Microwaving on Moisture, Ash and Protein Content of Whole Grain Wheat Flour

\begin{tabular}{ccccccc}
\hline Storage & \multicolumn{2}{c}{ Moisture \% (NIR) } & \multicolumn{2}{c}{ Ash \% (NIR) } & \multicolumn{2}{c}{ Protein \% (NIR) } \\
\cline { 2 - 7 } $\begin{array}{c}\text { Duration } \\
\text { Weeks) }\end{array}$ & MW & Non-MW & MW & Non-MW & MW & Non-MW \\
\hline 2 & $10.80 \pm 0.09^{\mathrm{a}}$ & $12.28 \pm 0.19^{\mathrm{a}}$ & $1.56 \pm 0.05^{\mathrm{a}}$ & $1.55 \pm 0.03^{\mathrm{a}}$ & $14.01 \pm 0.19^{\mathrm{bc}}$ & $13.81 \pm 0.12^{\mathrm{c}}$ \\
\hline 4 & $10.79 \pm 0.08^{\mathrm{a}}$ & $12.21 \pm 0.17^{\mathrm{a}}$ & $1.55 \pm 0.04^{\mathrm{a}}$ & $1.55 \pm 0.02^{\mathrm{a}}$ & $14.18 \pm 0.21^{\mathrm{bc}}$ & $14.08 \pm 0.09^{\mathrm{bc}}$ \\
\hline 6 & $10.96 \pm 0.05^{\mathrm{b}}$ & $12.28 \pm 0.09^{\mathrm{b}}$ & $1.54 \pm 0.02^{\mathrm{a}}$ & $1.56 \pm 0.02^{\mathrm{a}}$ & $14.21 \pm 0.15^{\mathrm{b}}$ & $13.98 \pm 0.08^{\mathrm{bc}}$ \\
\hline 8 & $10.67 \pm 0.07^{\mathrm{ab}}$ & $12.01 \pm 0.08^{\mathrm{b}}$ & $1.57 \pm 0.02^{\mathrm{a}}$ & $1.55 \pm 0.03^{\mathrm{a}}$ & $14.17 \pm 0.16^{\mathrm{b}}$ & $14.15 \pm 0.15^{\mathrm{b}}$ \\
\hline 10 & $10.87 \pm 0.09^{\mathrm{c}}$ & $12.11 \pm 0.15^{\mathrm{c}}$ & $1.56 \pm 0.06^{\mathrm{a}}$ & $1.55 \pm 0.02^{\mathrm{a}}$ & $14.12 \pm 0.14^{\mathrm{a}}$ & $14.12 \pm 0.09^{\mathrm{a}}$ \\
\hline 12 & $10.58 \pm 0.08^{\mathrm{cd}}$ & $12.19 \pm 0.08^{\mathrm{bc}}$ & $1.56 \pm 0.07^{\mathrm{a}}$ & $1.57 \pm 0.05^{\mathrm{a}}$ & $14.15 \pm 0.22^{\mathrm{a}}$ & $14.01 \pm 0.12^{\mathrm{a}}$ \\
\hline
\end{tabular}

MW - Microwaved Flour; Non-MW - Non-Microwaved flour

The values are means of triplicates \pm standard error

The means with the same letters are not significantly different at 5\% level 




The values are means of triplicates.

The vertical bars indicate the standard errors.

Figure 2: Impact of Storage and Microwaving on Wet-Gluten Content of Whole Grain Wheat Flour

\subsubsection{Fiber}

Table 2 reveals that the fiber content of both microwaved and non-microwaved flour increased throughout the storage period.

Table 2: Impact of Storage and Microwaving on the Fat and Fiber Content of Whole Grain Wheat Flour

\begin{tabular}{ccccc}
\hline $\begin{array}{c}\text { Storage } \\
\text { Duration } \\
\text { (Weeks) }\end{array}$ & Fat Content (\%) & \multicolumn{2}{c}{ Fiber Content (\%) } \\
\hline 4 & $4.53 \pm 0.02^{\mathrm{a}}$ & $3 . .37 \pm 0.07^{\mathrm{a}}$ & $1.07 \pm 0.02^{\mathrm{a}}$ & $1.02 \pm 0.09^{\mathrm{ab}}$ \\
8 & $3.30 \pm 0.03^{\mathrm{a}}$ & $3.77 \pm 0.08^{\mathrm{a}}$ & $1.67 \pm 0.04^{\mathrm{a}}$ & $1.53 \pm 0.04^{\mathrm{a}}$ \\
12 & $3.29 \pm 0.04^{\mathrm{a}}$ & $3.13 \pm 0.06^{\mathrm{ab}}$ & $1.72 \pm 0.05^{\mathrm{a}}$ & $1.80 \pm 0.05^{\mathrm{a}}$ \\
\hline
\end{tabular}

MW - Microwaved Flour; Non-MW - Non-Microwaved flour

The values are means of triplicates \pm standard error

The means with the same letters are not significantly different at $5 \%$ level 
The fiber content of the whole grain wheat flour was not affected by the microwaving. According to the statistical analysis, fiber content was not significant $(p>0.05)$ due to microwaving and storage. Fiber content of microwaved flour was increased from $1.07-1.72 \%$ whilst fiber content of nonmicrowaved flour falls between $1.02-1.80 \%$. But all the mean values were within specification.

\subsubsection{Fat Acidity}

As shown in Figure 3, fat acidity was increased during the storage period for both microwaved and non-microwaved flour.

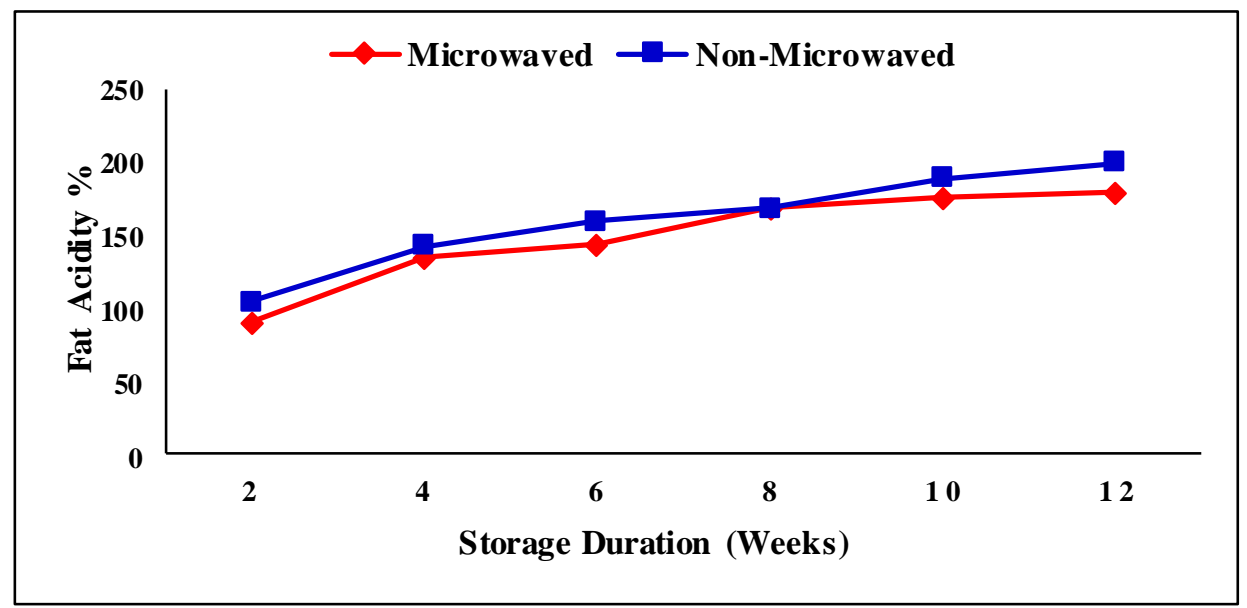

Figure 3: Impact of Storage and Microwaving on the Fat Acidity of Whole Grain Wheat Flour

Fat acidity of non-microwaved whole grain wheat flour was higher than the microwaved flour throughout the study period. According to the statistical analysis there was a significant effect $(\mathrm{p}<0.05)$ on fat acidity due to the storage period and microwaving. Fat acidity of the non-microwaved flour was nearly doubled at the end of the storage period. Whole wheat flour contains bran, germ and endosperm. Brans and germ have higher proportion of fat, so the problem of rancidity is higher than the white flour which is the major reason for poor shelflife of whole grain wheat flour. 
Wheat bran and germ have poor shelf-life due to the presence of unsaturated fatty acids, and oxidative and hydrolytic enzymes, rendering the product highly susceptible to rancidity since biologic and enzymatic activities of outer layer of the wheat kernel influence the whole wheat flour stability and bread properties during storage [16].

\subsubsection{Colour}

Color parameters are essential for consumers, who either purchase or select to consume food products, on the basis of their color. As shown in Figure 4, colour of the microwaved flour was higher the colour of the non-microwaved flour for total study period. So microwaving increased the colour content of the flour. Colour content of both flour fluctuated up to $6^{\text {th }}$ week then it decreased steadily up to $8^{\text {th }}$ week and then increased to reach $82.05-82.08 \%$ on $12^{\text {th }}$ week.

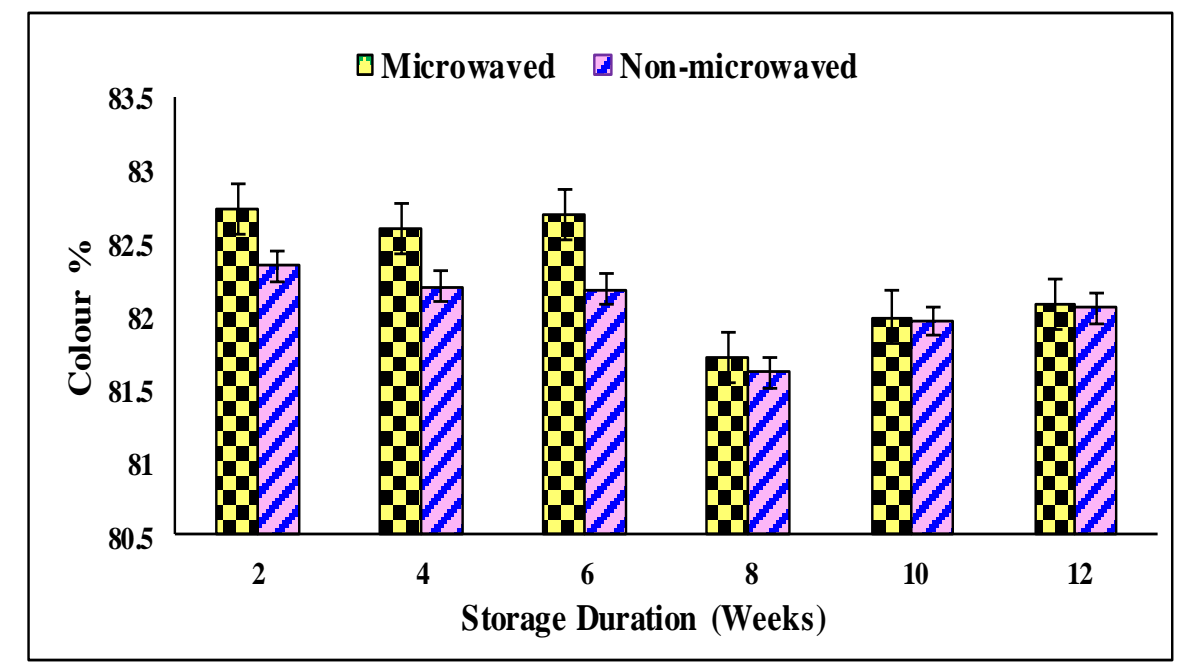

The values are means of triplicates.

The vertical bars indicate the standard errors.

Figure 4: Impact of Storage and Microwaving on the Colour of Whole Grain Wheat Flour

A research finding says that microwaving heat treatment reduces the considerable amount of phenolic compounds. So the flour colour of microwaved flour is lighter than the non-microwaved flour as the presence of less colour pigments. The loss of phenolic during drying might be due to the process conditions, in particular 
temperatures and the duration used [17]. Many researchers have found that Total Phenolic Compounds in various plant species have irregular change under different drying processes [18].

\subsection{Biological Parameter-Weevil Count}

Results obtained from the sieve test, there were no any weevils found in both microwaved and non-microwaved flour. All flours were weevil free throughout the study period.

\subsection{Sensory Evaluation}

According to the sensory evaluation (Figure: 5) general appearance, aroma, colour, taste, texture, mouth feel and over all acceptability of the healthy cake from non-microwaved flour were considerably better than the microwaved flour.

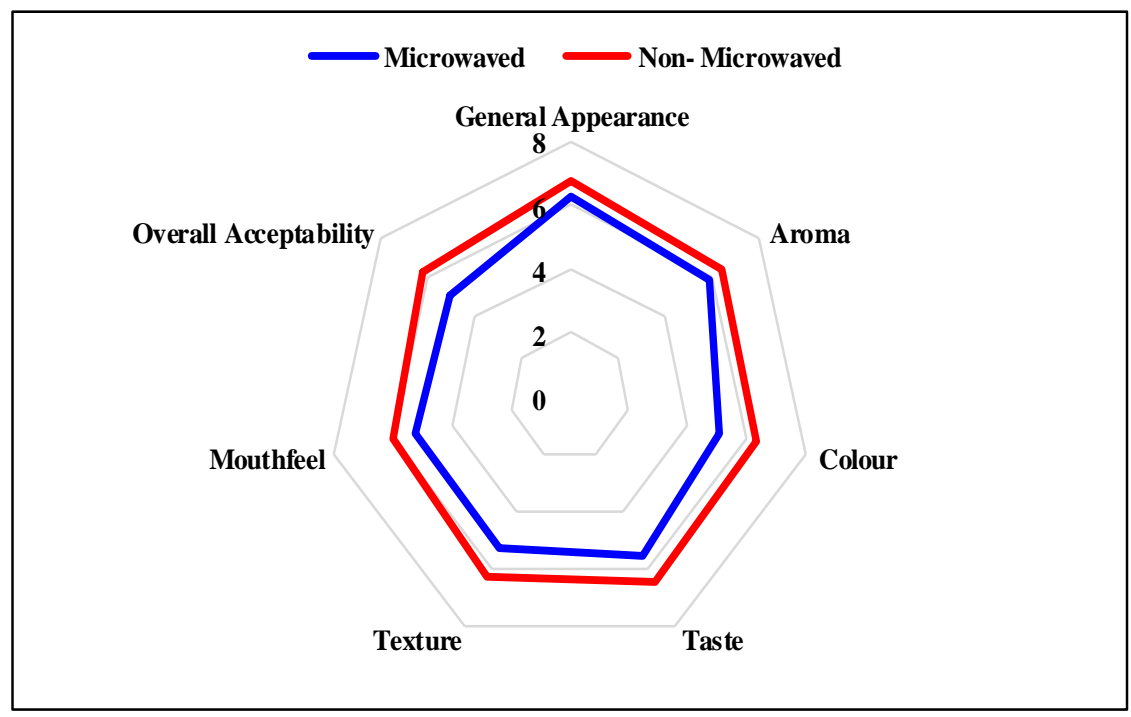

Figure 5: Sensory Evaluation of Healthy Cake from Whole Grain Wheat Flour following 12 weeks Storage

Aroma of the cake was not affected by the storage period. But colour, taste, texture and mouth feel were differed considerably due to aging of the flour for both cakes. The texture of the cake from non-microwaved flour was much better than the cake from microwaved flour. Texture of the cake prepared from 
microwaved cake deteriorated considerably with the storage period. Gluten influences specially texture and volume of the cake. Gluten content of the whole grain wheat flour decreased significantly which results in undesirable change in texture and also changes in lipid affected the quality of the cake. The volume and softness of steamed bread and morphology of short-dough biscuits is also influenced by lipids [19].

\subsection{CONCLUSIONS}

This study concludes that moisture content, colour, and fat acidity were significantly affected by microwaving treatment whilst other parameters wetgluten, protein, ash, fat and fiber not significant due to microwaving for whole grain wheat flour. On the other hand wet-gluten content, colour and fat acidity were significantly affected by storage period whereas moisture, protein, ash, fat and fiber of whole grain wheat flour were not considerably influenced by the storage period of 12 weeks of air-conditioned storage. In the case of healthy cake only textural changes were observed due to changes in gluten content during storage. So main aspect of this heat treatment is increased the shelf-life by reducing the moisture content and fat acidity. But, all the parameters of the both flours were remained within specification throughout the study period of 3 months under air-conditioned storage.

\section{REFERENCES}

[1]. Wrigley, C. W. (2009). Wheat: A unique grain for the World. Khan, K and Shewry, P. R. (Eds.) In Wheat Chemistry and Technology, Fourth Edition. pp 1-5, AACC International, Inc. St. Paul, MN.

[2]. Gooding, M. J. (2009). Wheat: A unique grain for the World. Khan, K and Shewry, P. R. (Eds.) In Wheat Chemistry and Technology. Fourth Edition. pp 1949, AACC International, Inc. St. Paul, MN.

[3]. Decker, E., Beecher, G., Slavin, J., Mileer, H. E. and Marquart, L. (2002). Whole grains as source of antioxidant. Cereal Food World. 47: 370-373.

[4]. Broekaert, W. F., Courtin, C. M., Verbeke, K., Van de Wiele, T., Verstraete, W. and Delcour, J. A. (2011). Prebiotic and other health-related effects of cerealderived arabinoxylans, arabinoxylan-oligosaccharides and xylooligosaccharides. Critical Reviews in Food Science and Nutrition. 51(2): 178-94. 
[5]. Vocke, G., Buzby, J. C. and Wells, H. F. (2008). Consumer preferences change wheat flour use. Amber Waves. 6: 2-11.

[6]. Sosland, L. J. (2011). Whole wheat flour production tops 20 million cwts; growth rate slows. Milling and Baking News. 90: 1-32.

[7]. Khamis, M. (2014). Characterization and evaluation of heat treated wheat flours. PhD dissertation, Kansas State University, Manhattan, Kansas.

[8]. Wang, L. and Flores, R. A. (1999). Effect of wheat starch and gluten on tortilla texture. Cereal Chemistry. 76: 807-810.

[9]. AACC. (2000). International Approved Methods of the American Association of Cereal Chemists, 10th Ed. Methods 02-52 and 44-15A. The Association: St. Paul, MN. 71-89.

[10]. Elżbieta, B. and Adam, E. (2007). Application of instrumental colour measurement as an indicator of changes occurring in wheat bakery products during production process. Polish Journal of Food and Nutrition Science. 57 (2): 29-34.

[11]. Meilgaard, M., Civille, G. V. and Carr, B. T. (1999). Sensory evaluation techniques. ( $3^{\text {rd }}$ Ed.) Boca Raton: CRC Press.

[12]. Osama, S. M., Wand, K. A. and Abdul, T. H. (2012). The effect of infestation by the confused flour beetle (Tribolium confusum Duv.) on specifications of wheat flour. Journal of Agricultural Science and Technology. 2: $696-701$.

[13]. Rehman, Z. and Shah, W. H. (1999). Biochemical changes in wheat during storage at three temperatures. Plant Foods for Human Nutrition. 54: 109-117.

[14]. Eleazu, C. and Eleazu, K. (2012). Determination of the proximate composition, total carotenoid, reducing sugars and residual cyanide levels of flours of 6 new yellow and white cassava (Manihot esculenta Crantz) varieties. American Journal of Food Technology. 7: 642-649.

[15]. Agrahar-Murugkar, D. and Jha, K. (2011). Influence of storage and packaging conditions on the quality of soy flour from sprouted soybean. Journal of Food and Technology. 48: 325-328. 
[16]. Sudha, M. L., Baskaran, V. and Leelavathi, K. (2007). Apple pomace as a source of dietary fiber and polyphenols and its effect on the rheological characteristics and cake making. Food Chemistry. 104(2): 686-692.

[17]. Schieber, A, Stintzing, F. C. and Carle, R. (2001). Byproducts of plant food processing as a source of functional compounds -recent developments. Trends in Food Science and Technology. 12: 401-413.

[18]. Dewanto, V., Wu, X., Adom, K. K. and Liu, R. H. (2002). Thermal processing enhances the nutritional value of tomatoes by increasing total antioxidant activity. Journal of Agricultural and Food Chemistry. 50: 3010-3014.

[19]. Papantoniou, E., Hammond, E., Scriven, F., Gordon, M. H. and Schofield, J. D. (2004). Effects of endogenous flour lipids on the quality of short-dough biscuits. Journal of the Science of Food and Agriculture. 8: 1371-1380. 